Check for updates

Cite this: J. Mater. Chem. A, 2020, 8 , 18387

DOI: $10.1039 / d 0 t a 90182 b$

rsc.li/materials-a

\section{Correction: Steering the crystallization of perovskites for high-performance solar cells in ambient air}

Feng Wang, ${ }^{a}$ Ting Zhang, ${ }^{a}$ Yafei Wang, ${ }^{a}$ Detao Liu, ${ }^{a}$ Peng Zhang, ${ }^{a}$ Hao Chen, ${ }^{a}$ Long Ji, ${ }^{a}$ Li Chen, ${ }^{a}$ Zhi David Chen, ${ }^{\text {ab }}$ Jiang Wu, ${ }^{c}$ Xin Liu, ${ }^{c}$ Yanbo Li, ${ }^{c}$ Yafei Wang ${ }^{a}$ and Shibin $\mathrm{Li}^{\star a}$

Correction for 'Steering the crystallization of perovskites for high-performance solar cells in ambient air' by Feng Wang et al., J. Mater. Chem. A, 2019, 7, 12166-12175, DOI: 10.1039/C9TA02566A.

The authors regret that the conflict of interest statement in the published article was incomplete. The conflict of interest statement should read as follows:

The research being reported in this paper was supported by Advanced Semiconductor Processing Technology, LLC (ASPT). One author of this paper, Prof. Zhi David Chen, has equity ownership in and serves as CEO/CTO for ASPT. ASPT does not develop any product related to the research being reported here. The terms of this arrangement have been reviewed and approved by the University of Kentucky in accordance with its responsible conduct of research policies.

The Royal Society of Chemistry apologises for these errors and any consequent inconvenience to authors and readers. 